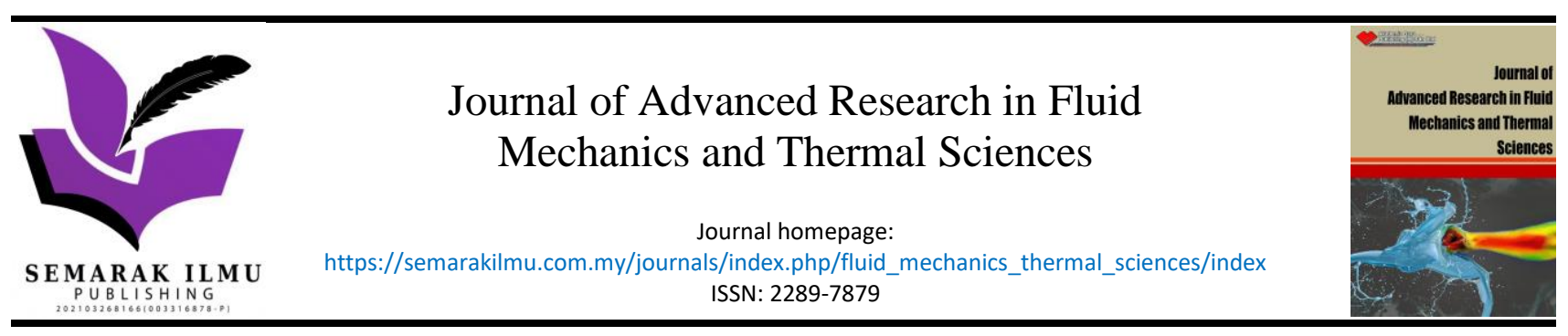

\title{
Waste Heat Recovery of Biomass Based Industrial Boilers by Using Stirling Engine
}

\author{
Nik Kechik Mujahidah Nik Abdul Rahman ${ }^{1}$, Syamimi Saadon ${ }^{1,}{ }^{,}$, Mohd Hasrizam Che Man ${ }^{2}$ \\ 1 Department of Aerospace Engineering, Faculty of Engineering, Universiti Putra Malaysia, 43400 Serdang, Selangor, Malaysia \\ 2 Mechanical Precision Engineering, Malaysia-Japan International Institute of Technology (MJIIT), Universiti Teknologi Malaysia, Jalan Semarak, \\ 54100 Kuala Lumpur, Malaysia
}

\section{ARTICLE INFO}

\section{Article history:}

Received 5 May 2021

Received in revised form 2 September 2021

Accepted 6 September 2021

Available online 15 November 2021

\section{Keywords:}

Biomass; Waste heat recovery; low temperature; work done; Stirling engine

\section{ABSTRACT}

Industrial boilers by using biomass for electricity generation have received significant attention recent years. However, during the process, a significant fraction of thermal energy is often lost to the environment as flue gas. The exhaust flue gas heat loss which ranges from $150-180^{\circ} \mathrm{C}(423.15-453.15 \mathrm{~K})$ has led to discovery of importance of recovering the waste heat of the flue gas to overcome the reliance on fossil fuel. Stirling engine as an external combustion engine with high efficiencies and able to use any types of heat source is the best candidate to recover waste heat of the exhausted gas by converting it into power. Thus, in this study Stirling engine was introduced in order to evaluate the possibility of recovering waste heat from industrial boilers to produce power. For this reason, Computational Fluid Dynamic (CFD) simulation test was performed to design an initial computational model of Stirling engine for low temperature heat waste recovery. The CFD model was validated with the experiment model and shows $4.3 \%$ of deviation. The validated model then connected to a lower temperature. It shows that when the heat source is $400 \mathrm{~K}$, the work done by the engine is $8.4 \mathrm{~J}$ compared to when heat source $773 \mathrm{~K}$ the work done is $17.0 \mathrm{~J}$. The computational model can be used to evaluate the performance of Stirling engine as waste heat recovery of biomass-based industrial boilers for low-grade temperature heat source.

\section{Introduction}

As the largest palm oil producer in the world, biomass in Malaysia has an advantage over other types of renewable energy replacing coal or natural gas that give benefits in reducing carbon dioxide emissions [1]. However, the usage of biomass as energy source in Malaysia is considered too small compared to th plantation and agricultural yield [2]. In biomass process, biomass pellets are used for domestic water heating, co-firing of pulverized biomass and coal for electricity generation. For most industrial boilers using biomass, the range of thermal efficiency is $60-90 \%$. The use of biomass to produce electricity by industrial boilers has a large fraction of thermal energy lost to the atmosphere. The temperature of the exhaust flue gas is low; usually, the temperature range is between $150-180^{\circ} \mathrm{C}$

\footnotetext{
* Corresponding author.

E-mail address: mimisaadon@upm.edu.my
}

https://doi.org/10.37934/arfmts.89.1.112 
(423.15-453.15K), and it can reach up to $220^{\circ} \mathrm{C}$ in some case [3]. For that reason, the heat loss from the exhausted flue gas has a significant potential to be recovered. Recovering heat as more as possible has great impact to environmental protection and energy conservation [4].

Stirling engine with high efficiencies and quit operation, as an external combustion engine is known for its ability to use any kind of heat source including solar, biological, geothermal, or even industrial waste heat compared to steamed engines [6]. Because of these characteristics, Stirling engine is the ideal candidate for low temperature waste heat recovery from flue gas and convert it into power [6]. Nevertheless, according to Bianchi and Pascale [7], the performance of the Stirling engine will decrease if attached with low temperature heat sources; between $200-500^{\circ} \mathrm{C}$. Therefore, study to enhance the heat transfer in the Stirling engine with low temperature heat sources should be taken into consideration.

The energy to power the Stirling engine movement is completely driven by an external source of energy, whereas energy in form of heat is added externally to the expansion chamber and removed from the compression chamber due to a differential temperature, generating work from the expansion and the compression of the working fluid [8]. Thus, the loses of heat happening during the heat transfer process in and out of the engine become important [9]. Hence, it is crucial to study methods for heat transfer enhancement for the external part of the tubular heater in order to achieve maximum efficiency of heat transfer for the best performance of the engine [10]. Earlier works have been done to study and explore the behaviour of this external heat transfer by adding different materials as heat transfer enhancement $[11,12]$. However, a more accurate validation is needed to strengthen the numerical result. Hence, this study is linking the gap of lacking research in studying the external part of tubular heater. Few researches have been done related to external part of the tubular heater of Stirling engine, disregarding the importance of this part in enhancing heat transfer as an external combustion engine.

In the study about the effect of radiation to the Stirling engine performance carried out by BenMansour et al., [13] stated that from the validation result, the power output of the system is between $30 \mathrm{~W}$ to $45 \mathrm{~W}$. The result obtained for every different rotational speed (rpm). A study of the beta type Stirling engine form Aksoy and Cinar [14] concluded that work done obtain from the Stirling engine with two different displacer surface is between 18J to 22J. These two related papers are used as the main reference for the geometry to perform the numerical analysis and for the validation purpose with the experimental result.

Stirling engine consists of many multi-dimensional components that its geometrical effects is very important to resolved the numerical models accurately. Computational fluid dynamic (CFD) approach is one of the numerical models that can simulating the multi-dimensional components and complicate processes in Stirling engine, hence gives an accurate prediction on the overall engine performance [5]. Therefore, CFD is used to perform this study.

In this study, Stirling engine was introduced in order to evaluate the possibility of recovering waste heat from industrial boilers to produce power. This paper presents the initial model for further improvisation for low temperature heat transfer process from the heat source to the external part of the tubular heater of the Stirling engine. The first of two parts of this paper shows the validation of the baseline model of Stirling engine according to the previous researcher. The second part presents the validated model attached with lower temperature as low as $400 \mathrm{~K}$ to evaluate its effect on the work done by the Stirling engine. This work is useful for further research in heat transfer enhancement in external part of Stirling engine for low temperature heat source. 


\section{Methodology}

\subsection{Governing Equation}

The flow field and heat transfer phenomena that happen in Stirling engine can be described mathematically by transient axisymmetric compressible Never-Stokes equations, conservation of energy equation, conservation of mass and ideal gas equations written as Eq. (1)-(8);

Mass equation:

$\frac{\partial \rho_{f}}{\partial_{t}}+\frac{\partial}{\partial x}\left(\rho_{f} \tilde{u}\right)+\frac{1}{r} \frac{\partial}{\partial r}\left(\rho_{f} r \tilde{v}\right)=0$

The momentum:

$\frac{\partial}{\partial t}\left(\rho_{f} u\right)+\frac{\partial}{d x}\left(\rho_{f} \tilde{u} u\right)+\frac{1}{r} \frac{\partial}{\partial r}\left(\rho_{f} r \tilde{v} u\right)=\rho_{f} g-\frac{\partial p}{\partial x}+\mu \frac{\partial}{\partial x}\left(\frac{\partial u}{\partial x}\right)+\frac{u}{r} \frac{\partial}{\partial r}\left(r \frac{\partial u}{\partial r}\right)+\frac{\mu}{3} \frac{\partial}{\partial x}(\nabla \cdot V)$
$\frac{\partial}{\partial t}\left(\rho_{f} v\right)+\frac{\partial}{d x}\left(\rho_{f} \tilde{u} v\right)+\frac{1}{r} \frac{\partial}{\partial r}\left(\rho_{f} r \tilde{v} u\right)=-\frac{\partial p}{\partial r}+\mu \frac{\partial}{\partial x}\left(\frac{\partial v}{\partial x}\right)+\frac{u}{r} \frac{\partial}{\partial r}\left(r \frac{\partial v}{\partial r}\right)+\frac{\mu}{3} \frac{\partial}{\partial r}(\nabla \cdot V)-\frac{\mu v}{r^{2}}$

Energy conservation:

$\frac{\partial}{\partial t}\left(\rho_{f} T_{f}\right)+\frac{\partial}{\partial x}\left(\rho_{f} \tilde{u} T_{f}\right)+\frac{1}{r} \frac{\partial}{\partial r}\left(\rho_{f} r \tilde{v} T_{f}\right)=-\frac{1}{c_{p f}}\left[\frac{\partial p}{\partial t}+\nabla \cdot(p V)-p(\nabla \cdot V)\right]+\frac{k f}{c_{p f}}\left[\frac{\partial}{\partial x}\left(\frac{\partial T_{f}}{\partial x}\right)+\right.$

$\left.\frac{1}{r} \frac{\partial}{\partial r}\left(r \frac{\partial T_{f}}{\partial r}\right)\right]+\frac{\mu}{c_{p f}}\left\{2\left[\left(\frac{\partial u}{\partial x}\right)^{2}+\left(\frac{\partial v}{\partial r}\right)^{2}+\left(\frac{v}{r}\right)^{2}\right]+\left(\frac{\partial v}{\partial x}+\frac{\partial u}{\partial r}\right)^{2}-\frac{2}{3}(\nabla \cdot V)^{2}\right\}$

Ideal gas equation:

$\rho V=\rho_{f} R T_{f}$

Displacement of piston and displacer;

$X_{p}(t)=L_{p t}+R_{d} \sin \theta+\left[l_{2}^{2}-\left(\frac{L}{2}-\frac{l_{1}}{2}-R_{d} \cos \theta\right)^{2}\right]^{0.5}$

Velocity of piston and displacer;

$X_{d}(t)=L_{d t}+R_{d} \sin \theta+\left[l_{2}^{2}-\left(\frac{L}{2}-\frac{l_{1}}{2}-R_{d} \cos \theta\right)^{2}\right]^{0.5}$

Velocity of the piston:

$u_{p}(t)=R_{d} \omega\left\{\cos \theta-\sin \theta\left[l_{2}^{2}-\left(\frac{L}{2}-\frac{l_{1}}{2}-R_{d} \cos \theta\right)^{2}\right]^{-0.5}\left[\frac{L}{2}-\frac{l_{1}}{2}-R_{d} \cos \theta\right]\right\}$ 
Velocity of the displacer:

$u_{d}(t)=R_{d} \omega\left\{\cos \theta+\sin \theta\left[l_{2}^{2}-\left(\frac{L}{2}-\frac{l_{4}}{2}-R_{d} \cos \theta\right)^{2}\right]^{-0.5}\left[\frac{L}{2}-\frac{l_{4}}{2}-R_{d} \cos \theta\right]\right\}$

\subsection{Modelling and Geometry}

Computational fluid dynamics (CFD) modelling is used in this study. ANSYS fluent 20.1 is used to solve the continuity, momentum and energy. The wall features and thickness were detailed in the wall boundary condition to include the conduction heat transfer through external wall was solved by the software. There are very few computational works in the literature that fully provides a complete information about geometry and boundary conditions that is needed to design geometry for the CFD simulations. The computational analysis from Ben-Mansour et al., [13] provides a concise information needed for the CFD simulation. Hence, his paper will be referred for the initial geometry of model of Stirling engine before adding the flue gas and heater chamber at the tubular heater of the engine.

In this study a rhombic drive mechanism $\beta$-type Stirling engine which consists of three zones; compression zone, expansion zone, and narrow zone as shown in Figure 1 is arrogated as an example. The narrow zone which connects the expansion and compression zone is initially assumed to have no regenerator materials. The dimensions of the geometries are stated in Table 1.

As shown in Figure 2, the simulation will be solved as 3D geometry. Air is utilized and treated as an ideal gas in this study. Air is assumed to be dependent on the gas temperature. The dimension of simulated geometry of the Stirling engine is stated in Table 1 . The cylinder wall features, and thickness is detailed in the wall boundary condition is as shown in Table 2. The thermal boundary conditions are limitedly between $775 \mathrm{~K}$ for hot temperature $\left(T_{H}\right)$ and $300 \mathrm{~K}$ for cold temperature $\left(T_{C}\right)$.

To ensure that the model is viable, further analysis on the work done by the engine is performed and compared with the experimental data of work done reported by Aksoy and Cinar [14]. The model then will be used for further evaluation with lower temperature of heat sources.

Geometry of Stirling engine used in CFD simulation is generated in Solidworks 2019. Figure 2(b) shows physical domain of Stirling engine with outer diameter of $90 \mathrm{~mm}$ and height of $213.12 \mathrm{~mm}$. The displacer is located $13.98 \mathrm{~mm}$ from the bottom surface, has diameter of $132.73 \mathrm{~mm}$ and height of $155 \mathrm{~mm}$. 


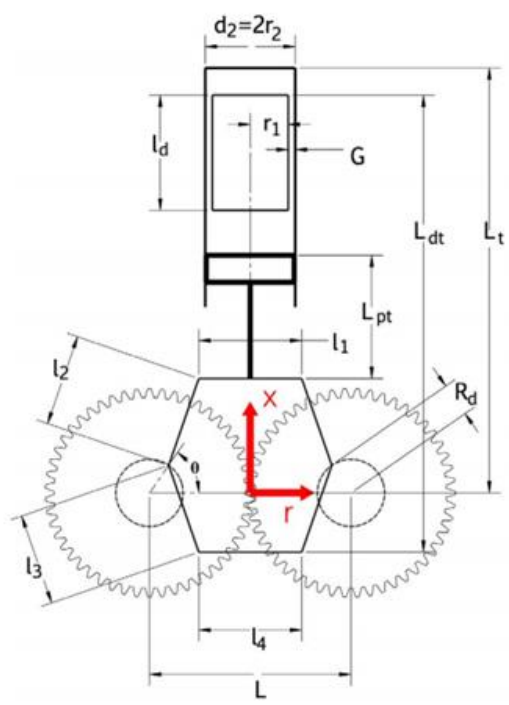

Fig. 1. Engine configuration [12]

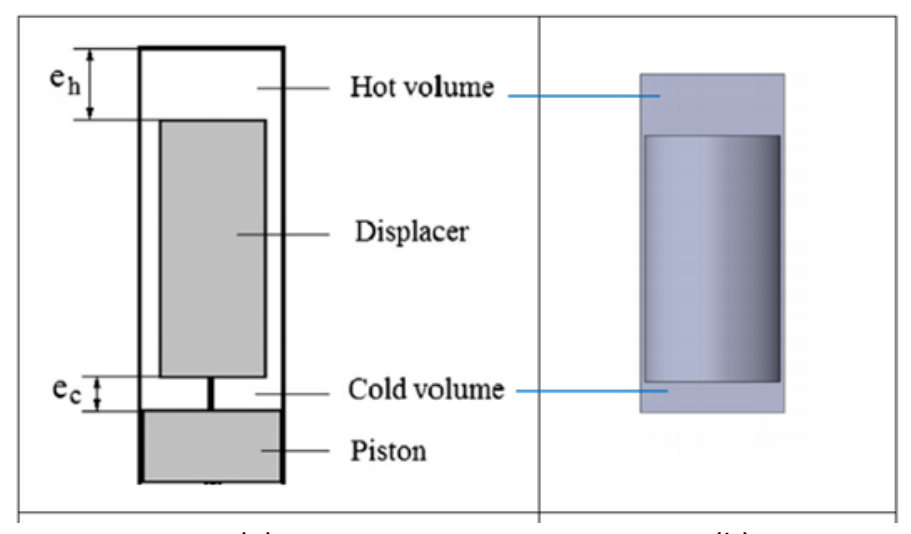

(a)

Fig. 2. (a) Schematic diagram and (b) CFD Domain

Table 1

Dimension of simulated geometry of the Stirling engine

\begin{tabular}{ll} 
in $(\mathrm{mm})$ & \\
\hline Working fluid & Air \\
\hline $\mathrm{r}_{1}$ & 43 \\
$\mathrm{r}_{2}$ & 42.25 \\
$\mathrm{l}_{\mathrm{d}}$ & 155 \\
$\mathrm{l}_{1}=\mathrm{l}_{2}=\mathrm{l}_{3}=\mathrm{l}_{4}$ & 66 \\
$\mathrm{R}_{\mathrm{d}}(\mathrm{mm})$ & $\mathrm{l}_{1} / 2.6666$ \\
$\mathrm{~L}_{\mathrm{pt}}$ & 50.93 \\
$\mathrm{~L}_{\mathrm{dt}}$ & 163.74 \\
$\mathrm{R}_{\mathrm{d}}$ & 3.5 \\
Engine speed & $500 \mathrm{rpm}$ \\
\hline
\end{tabular}

\section{Table 2}

Cylinder wall dimensions and properties

\begin{tabular}{ll}
\hline Thickness $(\mathrm{mm})$ & 1 \\
\hline Material & Steel \\
Density $\left(\mathrm{kg} / \mathrm{m}^{3}\right)$ & 7840 \\
Thermal conductivity & 43 \\
$\left(\mathrm{Wm}^{-1} \cdot \mathrm{k}^{-1}\right)$ & \\
Specific heat $\left(\mathrm{J} \cdot \mathrm{kg}^{-1} \cdot \mathrm{K}^{-1}\right)$ & 450 \\
\hline
\end{tabular}

\subsection{Mesh and Boundary Condition Setup}

To simplify the analysis, the Stirling engine domain is divided into four volumes, namely as displacer top volume, displacer bottom volume, engine gap volume and piston volume as shown in Figure 3. It is also divided into four sub-domains (volumes) to have a better control of mesh generated to reduce number of element and reduce computational time. The generated geometry is exported into Parasolid format (.x_t) to be imported into ANSYS Design modeler. 

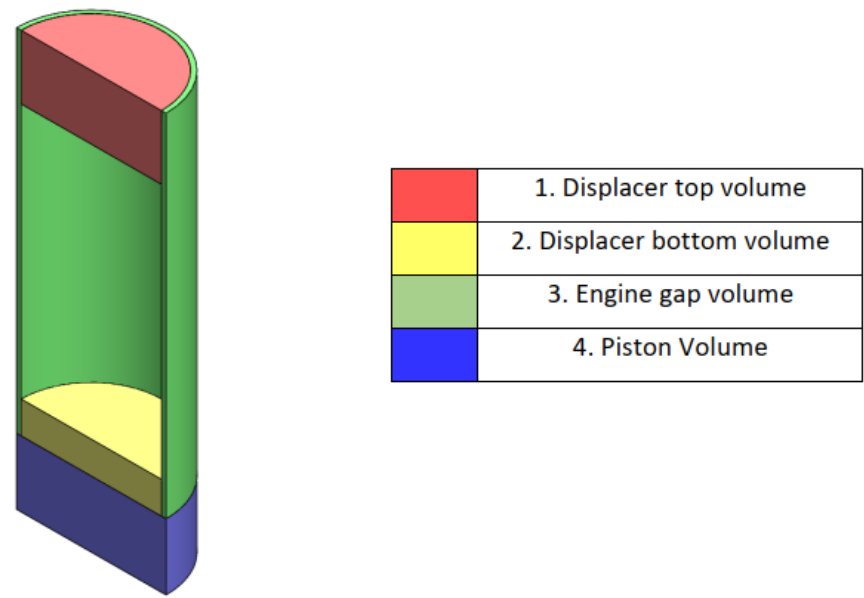

Fig. 3. Four volume of Stirling engine generated in crosscut at mid-plane

The user-defined function (UDF) and dynamic mesh is applied for the movement of the piston and displacer at transient condition. Layering mesh method is used in dynamic mesh function. Air is utilized as working fluid and set as the ideal gas. The thermal boundary condition was shown at 773K for the heating surface and $300 \mathrm{~K}$ for the piston surface for the validation model, and the heating surface is changed to heat source $600 \mathrm{~K}, 500 \mathrm{~K}$ and $400 \mathrm{~K}$ for lower temperature analysis. The basis pressure is in the Stirling engine cycle for this study is 1The analysis is pressure based with unsteady RANS(URANS). Analysis performed with Energy model turned on with k-omega SST turbulence model. The equations then were discretized with the Coupled Scheme Pressure-velocity coupling algorithm because it shows a relatively fast convergence compared to SIMPLE scheme [8]. The second-order upwind scheme is used for the density, momentum and energy equations while the first-order upwind scheme is used for the turbulent kinetic energy and specific dissipation rate.

Figure 4(a) shows overall mesh in this study, with minimum and maximum cells size are $1.5 \mathrm{~mm}$ and $2.5 \mathrm{~mm}$, respectively. Minimum cells size is for the regenerator area(gap) between displacer and engine that is so narrow and very crucial to apply dense mesh. All the mesh generated using structured mesh with combination of hexahedral and quadrilateral 3D elements with total cell number of 87,882 . Figure 4 (b) shows mesh at the gap between displacer and engine gap with element size of $1.5 \mathrm{~mm}$. Temperature source defined in boundary condition as shown in Figure 5 for cold surface and hot surface. 


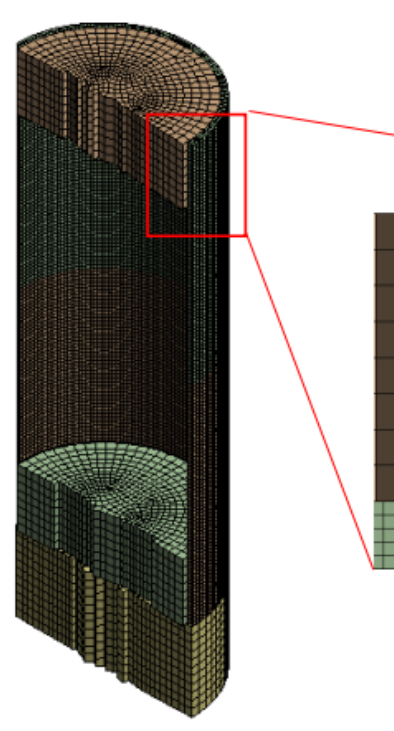

(a)

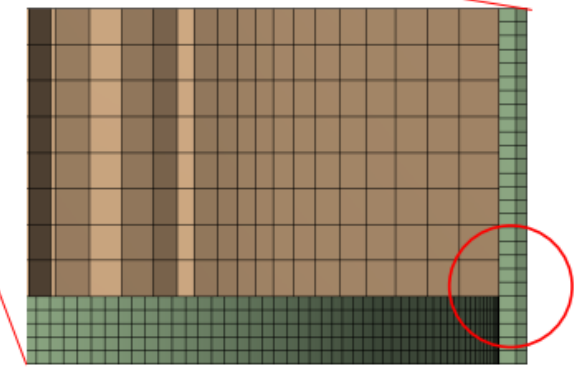

(b)

Fig. 4. Mesh generated for this study (a) overall mesh (b) refined mesh at the engine gap

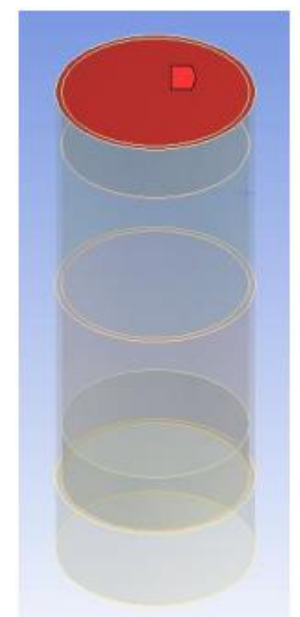

(a)

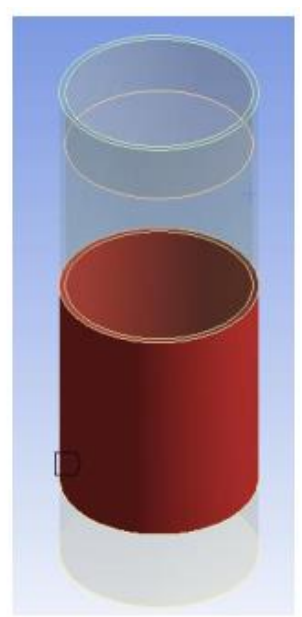

(b)

Fig. 5. Two boundary conditions for heat source (a) hot surface and (b) cold source surface

\section{Results}

\subsection{Model Validation}

This section discusses the results of Stirling engine validation. The model is validated by comparing the simulation results obtained from this study with the experimental results that were obtained in the study by Aksoy and Cinar [14]. Figure 6 shows the comparison of pressure-volume relation of experimental result and CFD result obtained from this study. The pressure value is taken from the pressure in the cold volume every time step of the engine cycle. While the volume is the area of the displacer surface and the height of cold volume in every time step. From this result, the work done by the system can be derived by integrating the area of this $p$-V diagram according to the Eq. (8) stated below [15].

$$
W_{\text {out }}=\frac{\omega}{2 \pi} \sum_{i=1}^{N} 0.5\left(p_{i-1}+p_{i}\right) \cdot\left(V_{i}-V_{i-1}\right)
$$


It has shown that the work done by this system in experiment is $18.4 \mathrm{~J}$ while CFD result shows that the work done is $17.0 \mathrm{~J}$. This result shows a $4.3 \%$ of deviation of the numerical modelling from the real process. Although the comparison result shows a small deviation, as the preliminary result, it can be further improved and exploited in order to determine the best method for the heat transfer in Stirling engine especially from the heat source into the top volume of the Stirling engine.

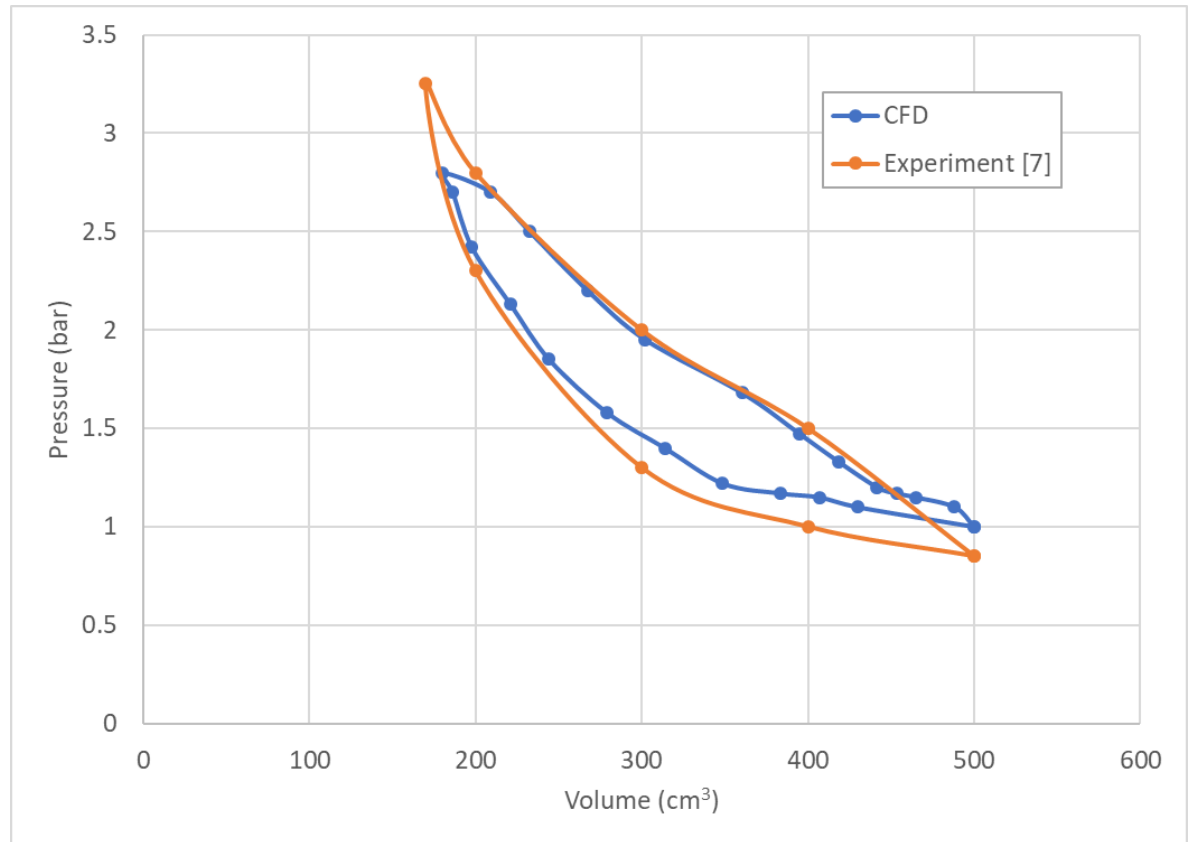

Fig. 6. Volume and Pressure relation between experiment and CFD

\subsection{Lower Temperature of Heat Source}

\subsubsection{P-V diagram}

From the validated model, the simulations for the lower temperature of heat sources have been conducted to study the effect of low temperature of heat source to the work done of the engine. Volume and pressure in cold volume is taken into consideration to calculate the work done. Three value of heat source temperature were tested which are $600 \mathrm{~K}, 500 \mathrm{~K}$ and $400 \mathrm{~K}$. These values then were compared to see the dynamic pressure pattern in every temperature. The dynamic pressure pattern for each low temperature in Figure 7. shows that the dynamic pressure decreases along when lower temperature is connected as the heat source at the top of the hot volume. The dynamic pressure is taken into consideration because it shows how the working fluid flows in the cold volume with certain velocities under different temperature.

However, for the work done of the engine, temperature of $773 \mathrm{~K}$ is compared with the lowest temperature tested $400 \mathrm{~K}$ to see the possibility of using heat source temperature as low as $400 \mathrm{~K}$. Result in Figure $8(\mathrm{a})$ shows that when the heat source is $773 \mathrm{~K}$, the work done by the engine is $17.0 \mathrm{~J}$, when the heat source is $400 \mathrm{~K}$, the work done by the engine is $10.4 \mathrm{~J}$. It shows the relation of the lower the heat source temperature, the lower the pressure in the cold volume which leads to a lower work done by the engine. Despite that some point is scattered, the trend of the volume and power of the cycle is same. Uneven curve shape of $400 \mathrm{~K} P-V$ diagram is assumed related to the mesh or grid quality in the computational analysis, especially in the narrow gap between the wall and the displacer. Figure 8 (b) and Figure 8 (c) shows P-V diagram when the heat source is $600 \mathrm{~K}$ and $500 \mathrm{~K}$. 
cold-volume

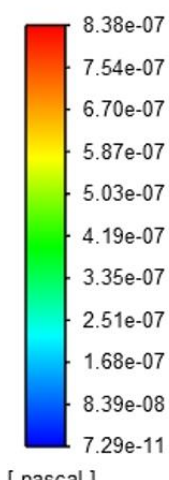

[ pascal ]

cold-volume

Dynamic Pressure

$6.99 \mathrm{e}-07$
$6.29 \mathrm{e}-07$
$5.60 \mathrm{e}-07$
$4.90 \mathrm{e}-07$
$4.20 \mathrm{e}-07$
$3.50 \mathrm{e}-07$
$2.80 \mathrm{e}-07$
$2.10 \mathrm{e}-07$
$1.40 \mathrm{e}-07$
$7.00 \mathrm{e}-08$
$1.05 \mathrm{e}-10$
Dynamic Pressure
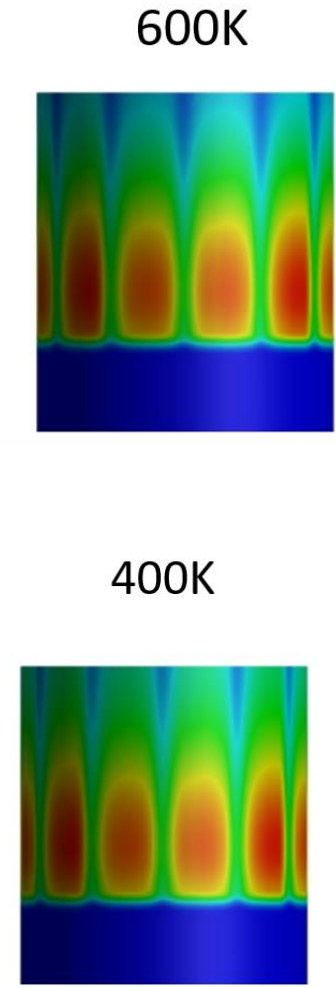

cold-volume-static

Dynamic Pressure

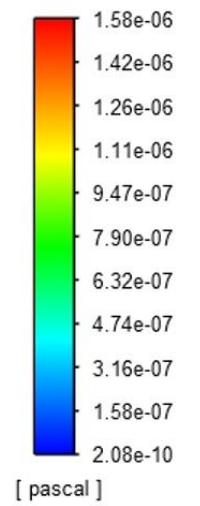

$773 K$

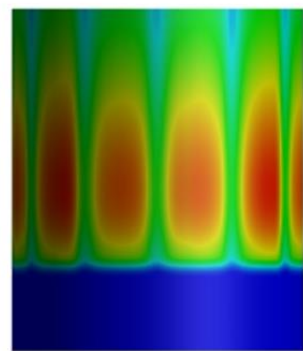

cold-volume
Dynamic Pressure

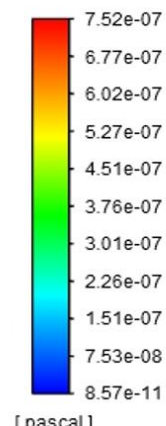

$500 \mathrm{~K}$

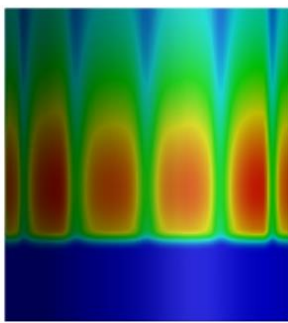

Fig. 7. Dynamic pressure distribution in cold volume of the cylinder engine for every temperature

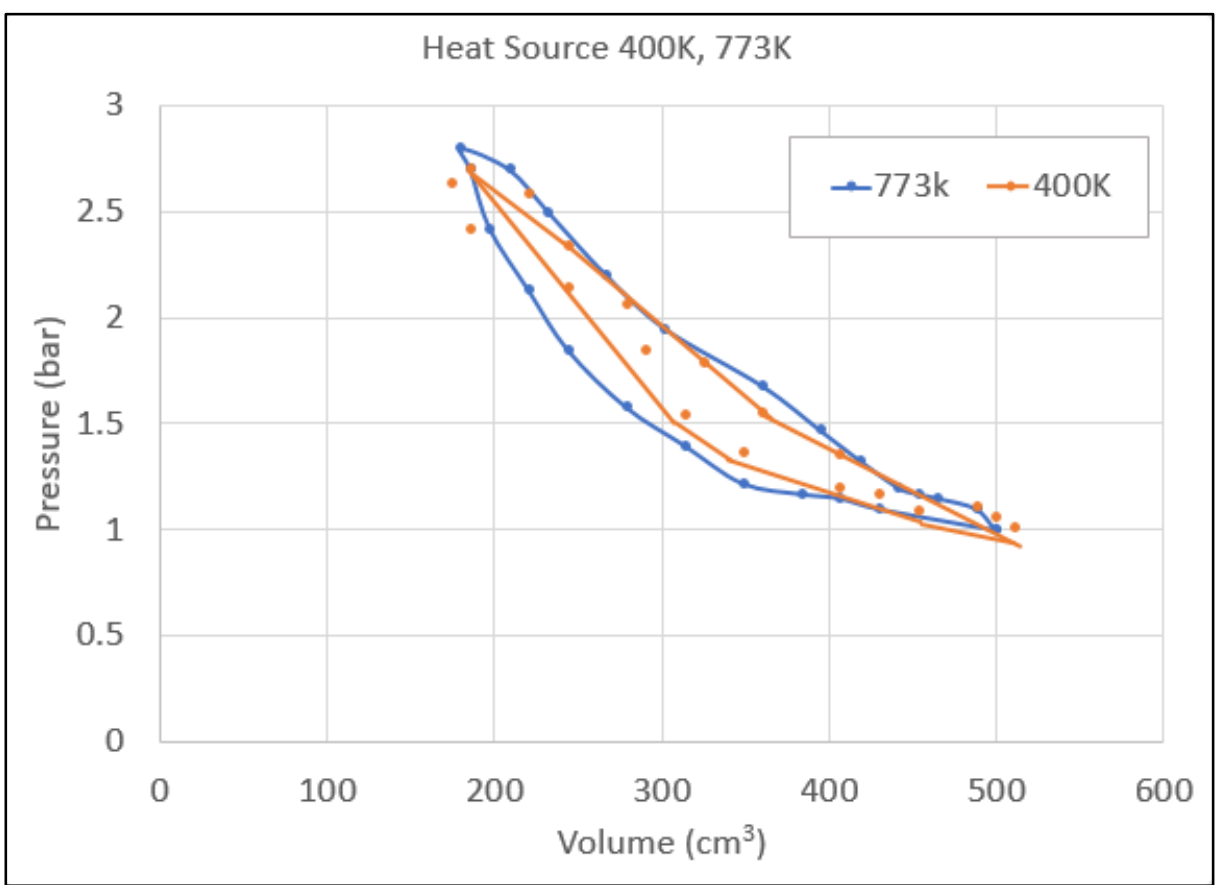

(a) 


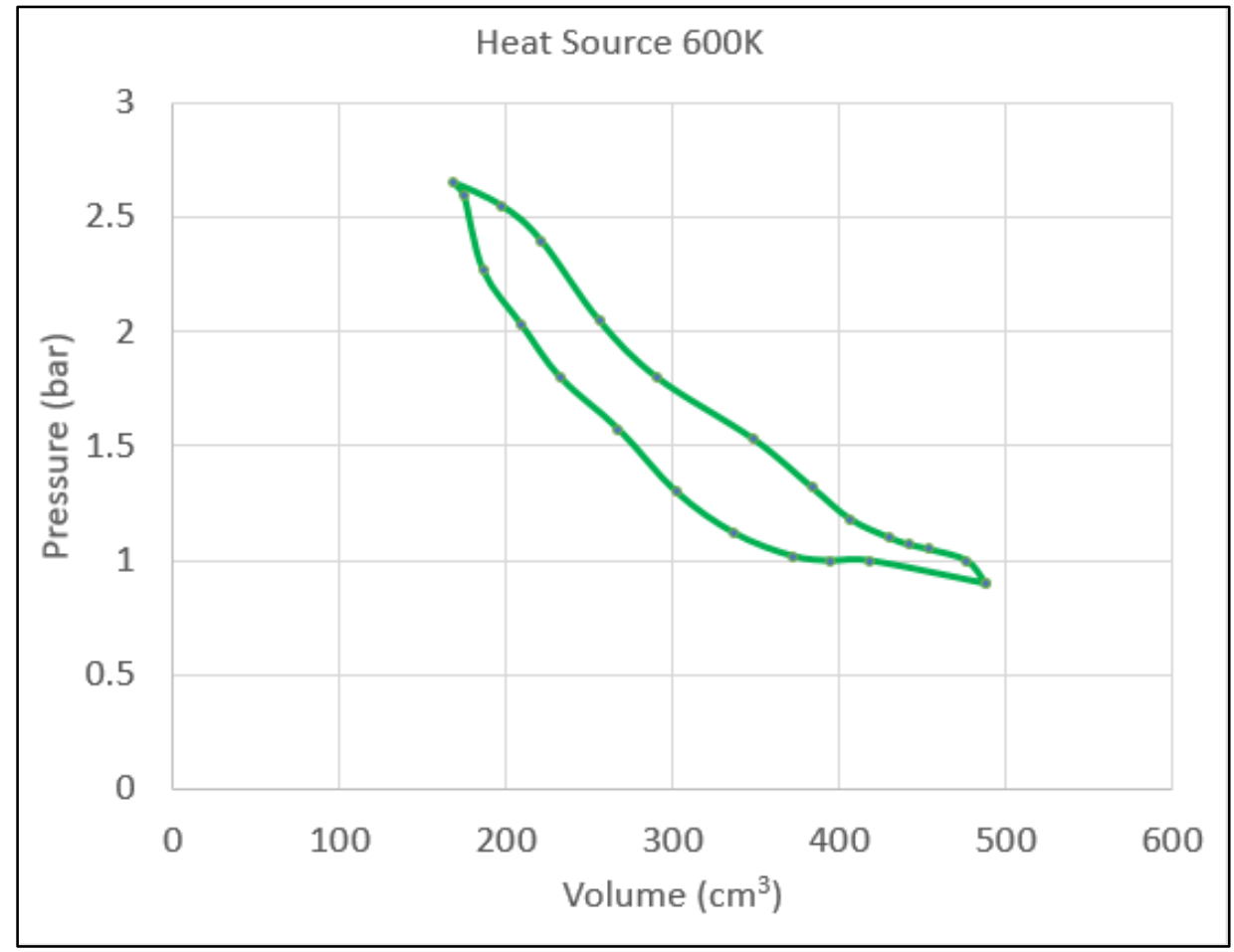

(b)

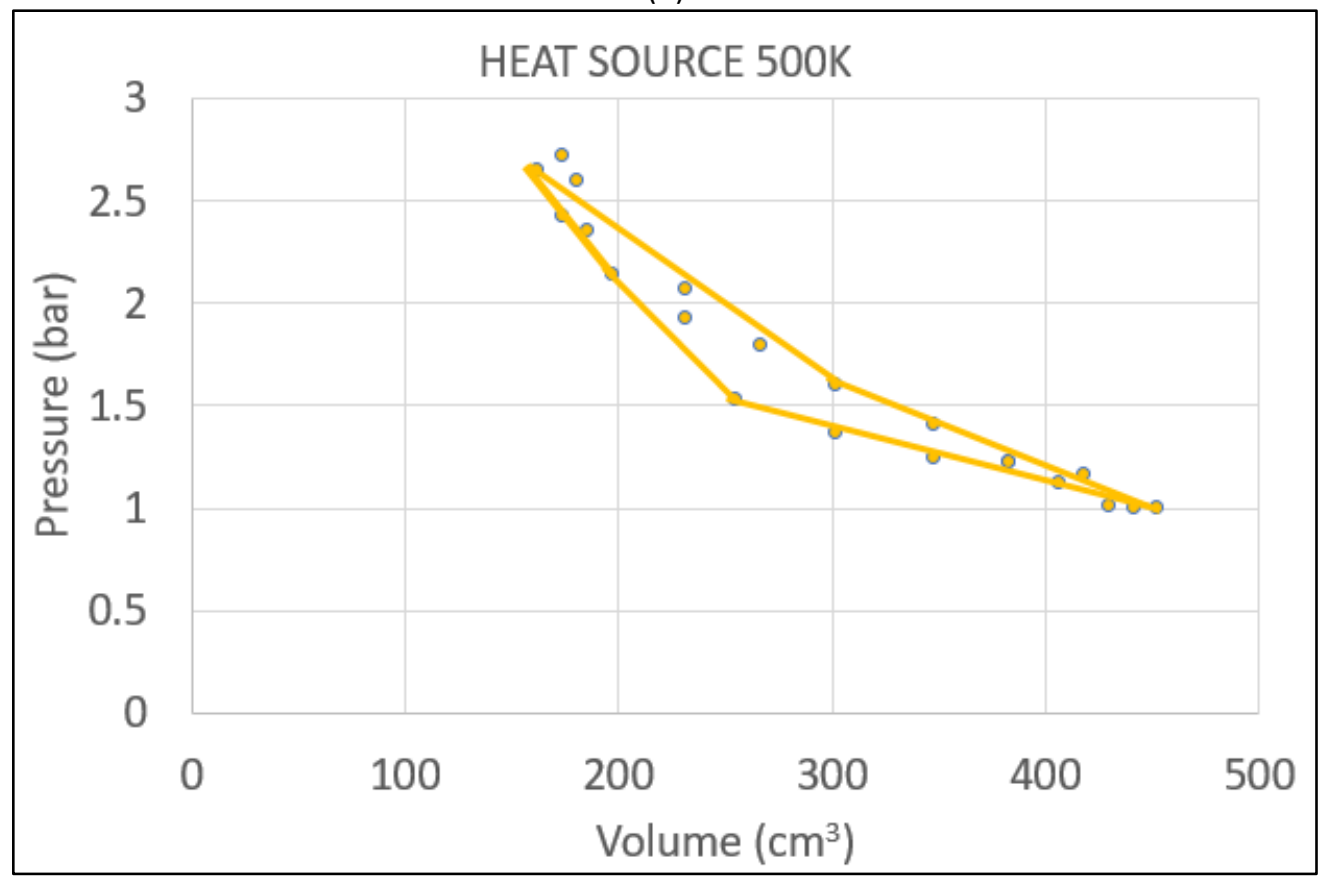

(c)

Fig. 8. Volume and Pressure relation between heat source temperature (a) $400 \mathrm{~K}$ and $773 \mathrm{~K}$ (b) $600 \mathrm{~K}$ and (c) $500 \mathrm{~K}$

From thermodynamic laws of energy, energy of a cycle depends on pressure and volume, whereas when the pressure and volume change, the output power of engine will also change. Temperature of hot side of engine causes pressure to rise and pushes the piston move down, piston's moving down changes volume thus it makes total temperature and total pressure inside cylinder that forces engine to run. $T_{C}$ and $T_{H}$ is temperature in cold volume and hot volume, $R$ is the ideal gas constant. $\mathrm{CR}$ is the compression ratio of the engine. 
The higher the temperature difference between hot and cold ends, the bigger work output can be obtained from the engine. So, it is important to optimize the heat transfer from the heat source to the hot volume of the cylinder to maximize the work done of the engine in lower temperature heat source.

\section{Conclusions}

The simulation data of Stirling engine model is presented here. This paper has introduced a heat transfer enhancement method of Stirling engine that is useful for the waste heat recovery system that can benefit in reducing the reliance on fossil fuel. The CFD result from the P-V diagram indicates that the work done by this system is $17.0 \mathrm{~J}$ which is $4.3 \%$ deviated from the work done obtained from the experimental result. From the validated model, it is compared with the lowest temperature tested $400 \mathrm{~K}$ to see the possibility of using heat source temperature as low as $400 \mathrm{~K}$. Result shows that when the temperature is $400 \mathrm{~K}$, the work done by the engine is $10.6 \mathrm{~J}$. It can be understood that the lower the temperature of heat source, the lower the work done by the engine. The heat transfer from the heat source to the hot volume affect the pressure and volume of the cold volume, hence, affect work done and power output of the engine.

Since an uneven curve is obtained in $\mathrm{p}-\mathrm{v}$ diagram of $400 \mathrm{~K}$ heat source, further analysis on the grid or mesh sensitivity test should be conducted to quantify the influence of the mesh resolution on the solution and to analyse the optimum mesh that will produces high accuracy in the computational work. This study can be further improved and exploited in order to determine the best method for the heat transfer in Stirling engine as the waste heat recovery system in low temperature heat source applications such as domestic water heating, co-firing of pulverized biomass and industrial boilers. The development of the Stirling engine in the waste heat recovery technology will gives advantages in reducing the usage of the fossil fuel to generate power consumption which will lead to lower fuel used and ultimately the $\mathrm{CO}_{2}$ emissions will be decreased. It is also can reduce the operational cost if the exhausted heat from the industrials can be recovered.

\section{Acknowledgement}

This research was funded by a grant from Ministry of Higher Education of Malaysia (FRGS Grant: FRGS/1/2018/TK07/UPM/02/2).

\section{References}

[1] Abdullah, Wan Syakirah Wan, Miszaina Osman, Mohd Zainal Abidin Ab Kadir, and Renuga Verayiah. "The potential and status of renewable energy development in Malaysia." Energies 12, no. 12 (2019): 2437. https://doi.org/10.3390/en12122437

[2] Ismail, H., A. A. Aziz, R. A. Rasih, N. Jenal, Z. Michael, and Azmi Roslan. "Performance of organic Rankine cycle using biomass as source of fuel." Journal of Advanced Research in Applied Sciences and Engineering Technology 4, no. 1 (2016): 29-46.

[3] Dehghan, Babak, Linwei Wang, Mario Motta, and Nader Karimi. "Modelling of waste heat recovery of a biomass combustion plant through ground source heat pumps-development of an efficient numerical framework." Applied Thermal Engineering 166 (2020): 114625. https://doi.org/10.1016/i.applthermaleng.2019.114625

[4] Li, Feng, Lin Duanmu, Lin Fu, and Xi ling Zhao. "Research and application of flue gas waste heat recovery in cogeneration based on absorption heat-exchange." Procedia Engineering 146 (2016): 594-603. https://doi.org/10.1016/i.proeng.2016.06.407

[5] Chen, Wen-Lih, King-Leung Wong, and Yu-Feng Chang. "A computational fluid dynamics study on the heat transfer characteristics of the working cycle of a low-temperature-differential $p$-type Stirling engine." International Journal of Heat and Mass Transfer 75 (2014): 145-155. https://doi.org/10.1016/i.ijheatmasstransfer.2014.03.055

[6] Song, Zhengchang, Jianmei Chen, and Li Yang. "Heat transfer enhancement in tubular heater of Stirling engine for waste heat recovery from flue gas using steel wool." Applied Thermal Engineering 87 (2015): $499-504$. 
https://doi.org/10.1016/i.applthermaleng.2015.05.028

[7] Bianchi, Michele, and Andrea De Pascale. "Bottoming cycles for electric energy generation: Parametric investigation of available and innovative solutions for the exploitation of low and medium temperature heat sources." Applied Energy 88, no. 5 (2011): 1500-1509. https://doi.org/10.1016/i.apenergy.2010.11.013

[8] Ahmadi, Mohammad H., Mohammad-Ali Ahmadi, and Fathollah Pourfayaz. "Thermal models for analysis of performance of Stirling engine: A review." Renewable and Sustainable Energy Reviews 68 (2017): 168-184. https://doi.org/10.1016/i.rser.2016.09.033

[9] Hsieh, Y. C., T. C. Hsu, and Jenq-Shing Chiou. "Integration of a free-piston Stirling engine and a moving grate incinerator." Renewable Energy 33, no. 1 (2008): 48-54. https://doi.org/10.1016/i.renene.2007.01.015

[10] Saadon, S. "Possibility of Using Stirling Engine as Waste Heat Recovery-Preliminary Concept." In IOP Conference Series: Earth and Environmental Science, vol. 268, no. 1, p. 012095. IOP Publishing, 2019. https://doi.org/10.1088/1755-1315/268/1/012095

[11] Helman, Harlinda, and Syamimi Saadon. "Design and Modelling of a Beta-Type Stirling Engine for Waste Heat Recovery." Journal of Advanced Research in Fluid Mechanics and Thermal Sciences 64, no. 1 (2019): 135-142.

[12] Rasli, Nur Amanina Mohamad, and Syamimi Saadon. "CFD Analysis of Heat Transfer Through Stirling Engine with Different Regenerators." Journal of Advanced Research in Fluid Mechanics and Thermal Sciences 64, no. 1 (2019): 126-134.

[13] Ben-Mansour, R., A. Abuelyamen, and Esmail M. A. Mokheimer. "CFD analysis of radiation impact on Stirling engine performance." Energy Conversion and Management $152 \quad$ (2017): $354-365$. https://doi.org/10.1016/j.enconman.2017.09.056

[14] Aksoy, Fatih, and Can Cinar. "Thermodynamic analysis of a beta-type Stirling engine with rhombic drive mechanism." Energy Conversion and Management $75 \quad$ (2013): $319-324$. https://doi.org/10.1016/i.enconman.2013.06.043

[15] Abuelyamen, A., R. Ben-Mansour, H. Abualhamayel, and Esmail M. A. Mokheimer. "Parametric study on beta-type Stirling engine." Energy Conversion and Management $145 \quad$ (2017): 53-63. https://doi.org/10.1016/i.enconman.2017.04.098 